\title{
Caracterização de diferentes classes genéticas de milho cultivados em região semiárida quanto ao potencial forrageiro
}

\author{
Characterization of different genetic classes \\ of maize cultivated in a semi-arid region \\ regarding the forage potential
}

\author{
Eduarda Santos Silveira ${ }^{1}$, Maisa Nascimento Carvalho ${ }^{2}$, \\ Beatriz Barreto de Lima ${ }^{1}$, Tâmara Rebecca Albuquerque de Oliveira ${ }^{1}$, \\ Gustavo Hugo Ferreira de Oliveira ${ }^{1}$
}

\footnotetext{
${ }^{1}$ Universidade Federal de Sergipe, Campus do Sertão (UFS), Núcleo de Graduação de Agronomia, Avenida Vinte e Seis de Setembro, 1126, CEP: 49680-000, Sergipe, Nossa Senhora da Glória, Brasil.

${ }^{2}$ Universidade Estadual Paulista "Júlio de Mesquita Filho"/ Faculdade de Ciências Agrárias e Veterinárias (UNESP),

Departamento de Fitotecnia, Via de Acesso Prof. Paulo Donato Castellane, S/N, CEP: 14884-900, São Paulo, Jaboticabal, Brasil.

e-mail: silveira12eduarda@gmail.com, biahbarreto97@hotmail.com, tamara_rebecca@ hotmail.com, gustavo.ufs@ufs.br, maisa.n.c@hotmail.com
}

\section{RESUMO}

O milho é bastante cultivado na região semiárida brasileira e contém alto valor energético na dieta animal. Sabendo disto, objetivou-se caracterizar diferentes classes genéticas de milho quanto ao seu potencial forrageiro nas condições semiáridas de Sergipe. Para isso, foram avaliados 36 genótipos em blocos incompletos em Látice quadrado reticulado 6x6, com duas repetições, na fazenda experimental da Embrapa - Semiárido, em Graccho Cardoso-SE. As variáveis analisadas foram: altura da planta, diâmetro do colmo, peso de planta, massa fresca, massa seca, porcentagem de massa seca e massa de forragem. Com os dados obtidos foi realizada análise de variância com auxílio do software SAS 9,4 e, para a geração dos componentes principais (CP) e gráficos, foi utilizado o software R com o pacote "GGEBiplotGUI". Todas as variáveis apresentaram diferenças significativas entre classes genéticas. Os dois primeiros componentes principais contemplaram $83,9 \%$ da variação total. O autovalor do primeiro CP (CP1) foi de 4,11, considerado muito significativo, já que a soma de todos os autovalores foi de 6,99. A porcentagem de massa seca, diâmetro do colmo, peso de planta, massa fresca, seca e de forragem obtiveram maior capacidade de discriminar as classes genotípicas. Os híbridos intervarietais ficaram mais próximos do genótipo "ideal”. A maior correlação positiva foi entre massa de forragem e massa seca. Os híbridos simples e triplos destacaram-se individualmente na altura da planta e porcentagem de massa. A massa seca e de forragem obtiveram maiores médias em todas as classes, exceto nos híbridos simples. As variedades foram as menos estáveis nas avaliações. Os híbridos intervarietais apresentaram maior potencial forrageiro e os duplos, topcross e variedades maior variabilidade genética, as demais classes não são indicadas para agricultores de baixa e média tecnologia quando cultivados em região semiárida para forragem de milho.

Palavras-chave: Zea mays L., Forragicultura, Melhoramento vegetal, Produção de silagem, Seca.

\section{ABSTRACT}

Corn is widely grown in the semi-arid region and contains high energy value in the animal diet. Thus, the aim of this study was to characterize different genetic classes of maize cultivated for forage potential in the semiarid conditions the Sergipe. For this, 36 genotypes were evaluated in incomplete blocks in lattice square reticulate 6x6, with two replications, in the experimental farm of Embrapa - Semiárido, in Graccho Cardoso-SE. The variables analyzed were: plant height, stem diameter, plant weight, fresh weight, dry weight, percentage of dry weight and forage weight. With the data obtained was accomplished an analysis of variance with the help of software SAS 9,4 and, for generation the principal component analysis (PCA) and graphics, was used 
the software R with the package "GGEBiplotGUI". All the variables showed significant differences between genetic classes. The first two main components included $83.9 \%$ of the total variation. The eigenvalues of the first PC (PC1) were 4,11, considering more significant, since the sum of all was of 6,99. The percentage of dry mass, stem diameter, plant weight, fresh, dry and forage mass obtained greater hability to discriminate genotypic classes. The intervarietal hybrids were closer to the "ideal" genotype. The greatest positive correlation was between forage weight and dry weight. The single and triple hybrids stood out individually in plant height and percentage of mass. The dry and forage mass obtained higher averages in all classes, except for simple hybrids. The varieties were the least stable in the evaluations. The intervarietal hybrids showed greater forage potential and the double, topcross and varieties had greater genetic variability, already to the genetic classes they are not indicated for farmers of low and mean tech in the semiarid region for forage of maize.

Keywords: Zea mays L., Forage, Plant breeding, Silage production, Drought.

\section{INTRODUÇÃO}

O milho é um dos principais grãos cultivados do mundo, junto a soja, arroz e trigo $[1,2]$. Sua maior demanda no Brasil vem da alimentação animal, onde os grãos de milho fazem parte da formulação de rações, pois apresentam um grande potencial energético sendo a principal fonte energética para a bovinocultura brasileira $[2,3]$. Além dos seus grãos, suas partes vegetativas são utilizadas para a produção de silagem que é um componente volumoso na formulação de rações [4].

Atualmente, segundo CONTINI et al. [5], os Estados Unidos e a China, juntos, representam 58,9\% da produção mundial, seguidos do Brasil e da União Europeia. Estes países e organização juntos são os maiores produtores de milho do mundo e representam $72,3 \%$ de toda produção da commoditie. Para o ano agrícola de 2020 foi estimado no mês de julho pelo Departamento de Agricultura dos Estados Unidos (USDA) uma safra global 2020/2021 de 1.163,21 milhões de toneladas [6], e, para o Brasil, uma safra de aproximadamente 102 milhões de toneladas [7].

Apesar da expansão da produção e cultivo do milho ser afetada pelos baixos níveis de precipitação [8, 9], como é o caso das regiões semiáridas e áridas do mundo, muitos agricultores produzem o milho para a ensilagem no período de maior concentração de chuvas, com a finalidade de, em épocas de seca prolongada, utilizar na alimentação dos animais. No semiárido brasileiro, por exemplo, o milho, mesmo não estando nas condições mais favoráveis, possui uma boa produção e grande importância socioeconômica e cultural [10].

As regiões de clima semiárido são caracterizadas pela ocorrência de altas temperaturas, altas taxas de evapotranspiração, má distribuição de chuvas e períodos longos de estiagem [11-13]. Por conta destes fatores limitantes, a implantação do milho neste tipo de clima só foi possível graças a criação de estratégias para o sucesso e estabelecimento da lavoura e, consequentemente, o aumento da produtividade [14], como é o caso dos programas de melhoramento, os sistemas de irrigação e a criação de novos programas governamentais voltadas ao semiárido $[15,16]$.

Apesar dos avanços tecnológicos e da chegada da agricultura de precisão ao Brasil, as áreas semiáridas ainda são vistas como atrasadas, menos desenvolvidas socioeconomicamente, e associadas a um local com alta degradação ambiental e pobreza [17]. Por conta disto e pelo pouco conhecimento dos produtores das regiões vulneráveis a seca, a escolha do cultivar de milho disponível no mercado ainda é falha, pois, muitas vezes, as cultivares ofertadas possuem características agronômicas que, para a produção de volumoso e tolerância a seca, podem não ser tão favoráveis [18]. É muito observado, ainda, a utilização de cultivares híbridas pelos agricultores, pois, estes não utilizam outras classes genéticas disponíveis por falta de conhecimento sobre a potencialidade de cada uma destas em sua região. Cada classe genética possui uma demanda de nível tecnológico utilizada no cultivo, para obterem respostas produtivas positivas da cultura [19].

No Nordeste, detentor da maior área do semiárido brasileiro, para o ano agrícola de 2020, foi estimado uma safra de 6.873,918 mil toneladas de milho, com uma possível alta de 5,4\% quando comparado ao ano anterior [20]. Este aumento na produção de milho no Nordeste brasileiro ressalta ainda mais a importância dos programas de melhoramento, pois a região possui um vasto histórico de perdas de produção [21].

Os trabalhos de melhoramento voltados as regiões vulneráveis a seca são complexos e levam tempo, pois as características agronômicas desejáveis para a produção de forragem são altamente influenciadas pelo ambiente, e é por isto que este fator afeta diretamente a produtividade da área rural do agricultor [22,23]. A partir destes trabalhos, diversas culturas não tolerantes a seca, como feijão, soja e o milho puderam ser cultivadas no semiárido em todo o mundo que, durante muito tempo, era resumida a uma agricultura limitada a subsistência [24].

Diante do exposto, o presente trabalho teve como objetivo caracterizar diferentes classes genéticas de milho quanto ao seu potencial forrageiro nas condições semiáridas sergipanas. 


\section{MATERIAIS E MÉTODOS}

O experimento foi desenvolvido no período da safra no Estado de Sergipe em 2018, na fazenda experimental da Embrapa - Semiárido, localizada no município de Graccho Cardoso, onde, segundo ALVAREZ et al. [25], de acordo com a classificação de Köppen, possui o tipo climático é o As, que é caracterizado por possuir o verão quente e seco e precipitação no mês mais chuvoso do verão. com precipitação média anual de $700 \mathrm{~mm}$ e temperatura média anual de $24^{\circ} \mathrm{C}$.

Durante o período de avaliação experimental, que compreendeu os meses de 24 de maio de 2018 a 09 de agosto de 2018, o maior valor de temperatura máxima foi de $24,9^{\circ} \mathrm{C}$ e o menor valor de mínima foi de $21,8^{\circ} \mathrm{C}$. já a umidade relativa variou de $84,9 \%$ máxima e $72,5 \%$ mínima. Ainda, durante o período, houve uma maior precipitação no mês de julho com um total de $61,4 \mathrm{~mm}$ e menor em agosto com $21,8 \mathrm{~mm}$, nos meses de maio e junho os valores foram próximos, sendo $46,8 \mathrm{~mm}$ e $41,8 \mathrm{~mm}$, respectivamente [26].

$\mathrm{O}$ experimento foi realizado em Campo, utilizando delineamento experimental em blocos incompletos em Látice quadrado reticulado $6 \times 6$ com duas repetições e, consequentemente, 36 tratamentos, totalizando 72 unidades experimentais. As parcelas foram constituídas de duas linhas de 4 metros de comprimento cada, com um espaçamento de $80 \mathrm{~cm}$ entre linhas e $20 \mathrm{~cm}$ entre plantas, onde na primeira e na última cova foram adicionadas duas sementes, totalizando 22 sementes por linha e, portanto, 44 sementes na parcela.

O manejo da adubação foi realizado seguindo a recomendação de fertilizantes para a cultura do milho no Estado de Sergipe, tendo como base a análise de solo da área [27]. As adubações foram realizadas manualmente, colocando-se o adubo no sulco de plantio. A adubação de fundação foi realizada um dia antes do plantio, onde utilizou-se $300 \mathrm{~kg} / \mathrm{ha}$ de NPK da formulação 10-30-10, e a adubação de cobertura foi realizada no estádio fenológico ente quatro e seis folhas totalmente expandidas, utilizando-se $143,75 \mathrm{~kg} / \mathrm{ha}$ de sulfato de amônio.

Foram utilizadas como tratamentos as sementes de 36 cultivares (Tabela 1), onde alguns são comerciais e outros experimentais, provenientes da Empresa Brasileira de Pesquisa Agropecuária (Embrapa) - Milho e Sorgo, localizada na cidade de Sete Lagoas - MG.

Tabela 1: Tipo, ciclo, fase e obtentor das cultivares avaliadas no experimento, conduzido na fazenda experimental da Embrapa Semiárido, localizada no município de Graccho Cardoso - SE, no ano agrícola de 2018.

\begin{tabular}{llllllll}
\hline Tipo & Genótipo & Ciclo & Fase & Tipo & Genótipo & Ciclo & Fase \\
\hline HS & BRS 1055 & P/N & Comercial & V & UFVM200(HS)C1 & P/N & Experimental \\
V & Sint 10771-BRS 4107 & P/N & Comercial & HTC & HTC-SP1 & SP & Experimental \\
V & Sint 10717 & P/N & Experimental & HTC & HTCms- CAPO & SP & Experimental \\
V & Sint 10795-BRS 4105 & P/N & Comercial & HTC & HTC771 & P/N & Experimental \\
V & UFVM100(HS)C1 & P/N & Experimental & HTC & HTC717 & P/N & Experimental \\
V & Potiguar-G13 & P/N & Comercial & HTC & HTC795 & P/N & Experimental \\
V & BRS Gorutuba & SP & Comercial & HTC & HTC707 & P/N & Experimental \\
V & CAPO & SP & Comercial & HTC & HTC781 & P/N & Experimental \\
V & BR5037-Cruzeta-G19 & SP & Comercial & HTC & HSmsxHTMV1 & P/N & Experimental \\
V & PC0904 & P/N & Experimental & HTC & HTC697 & P/N & Experimental \\
V & IPR164 & P/N & Experimental & HTC & HTCms15672 & P/N & Experimental \\
V & PC0905 & P/N & Experimental & HI & HI (771xHTMV1) & P/N & Experimental \\
V & Sint.Super Prec 1 & SP & Experimental & HI & HI (707x HTMV1) & P/N & Experimental \\
V & MC 50 & P/N & Experimental & HI & 98CV02 & P/N & Experimental \\
V & MC 20 & P/N & Experimental & HI & HIV 473451 & P/N & Experimental \\
V & MC 60 & P/N & Experimental & HI & HIV 2564260 & P/N & Experimental \\
V & AL 2015 & P/N & Experimental & HD & BR2121QPM & P/N & Comercial \\
V & AL AVARÉ & P/N & Comercial & HT & BRS 3046 & P/N & Comercial \\
\hline
\end{tabular}


HD = Híbrido Duplo; HS = Híbrido Simples; HI = Híbrido Intervarietal; HT = Híbrido Triplo; V = Variedade; HTC = Híbrido Topcross; $\mathrm{HI}=$ Híbrido Intervarietal; $\mathrm{P} / \mathrm{N}$ = Precoce/Normal; SP = Super-precoce.

As variáveis analisadas foram, altura da planta (AP), nesse caso obtido por meio da média de oito plantas da parcela por meio de uma régua graduada; diâmetro do colmo (DC), obtido pela média de oito plantas dentro da parcela com o auxílio de um paquímetro; peso de planta (PP), todas as plantas de cada parcela foram colhidas e pesadas em uma balança digital; peso médio de massa fresca (MFE), obtido pela média de duas amostras da parcela trituradas em forrageira e pesadas em balança digital; peso médio de massa seca (MS), foi obtida por meio de duas amostras da planta triturada, as quais foram depositadas em uma estufa a $56{ }^{\circ} \mathrm{C}$ por um período de três dias para a secagem do material, as amostras foram pesadas antes e depois de serem colocadas na estufa; porcentagem de massa seca (PorMS), obtida por meio da divisão entre MS e MFE e por último foi quantificado o peso médio de massa de forragem (MFO) por meio da expressão 1.

$$
M F=(\text { Peso de planta }(g) * \% M S) / 9,6 * 10
$$

Os dados obtidos foram avaliados de maneira que para efeito de análise os genótipos foram agrupados em classes genotípicas. Os componentes principais representam os autovetores usados para identificar os melhores genótipos. Os dois primeiros componentes principais (CP1 e CP2) apresentaram maior variabilidade e foram usados para o agrupamento das classes genotípicas. O método GT Biplot foi embasado usando a expressão 2 .

$$
Y i j-\bar{y}_{j}=y 1 \varepsilon i 1 \rho j 1+y 2 \varepsilon i 2 \rho j 2+\varepsilon i j
$$

Em que: Yij representa o rendimento médio da i-ésima classe genotípica na j-ésima variável; yj é a média geral das classes na variável j; y1 ei1 pj1 é o primeiro componente principal (CP1); y2 عi2 pj2 é o segundo componente principal (CP2); y1, y2 são os autovalores associados ao CP1 e CP2, respectivamente; $\varepsilon 1$ e $\varepsilon 2$ são os escores do primeiro e segundo componente principal, respectivamente, da i-ésima classe; $\rho j 1$ e $\rho j 2$ são os escores do primeiro e segundo componente principal, respectivamente, para a j-ésima variável; cij é o erro do modelo associado com a i-ésima classe e j-ésima variável [28].

Assim, o gráfico Biplot no modelo GT foi realizado por meio da dispersão simples de g1i e gi2 para genótipos e e1j e e2j para variáveis, por meio da Decomposição em Valores Singulares (DVS), conforme a equação: Yij $-\mu-\beta j=\lambda 1 \xi i 1 \eta 1 j+\lambda 2 \xi i 2 \eta 2 j+\varepsilon i j$, em que $\lambda 1$ e $\lambda 2$ são os maiores autovalores do primeiro e segundo componentes principais ACP1 e ACP2, respectivamente; $\xi$ i1 e $\xi$ i2 são os autovetores do i-ésimo genótipo para ACP1 e ACP2, respectivamente; e $\eta 1 \mathrm{j}$ e $\eta 2 \mathrm{j}$ são os autovetores do j-ésimo variáveis para $\mathrm{ACP} 1$ e ACP2, respectivamente. As análises foram realizadas com o auxílio do software R (R Development Core Team, 2014), com o pacote "GGEBiplotGUI".

\section{RESULTADOS E DISCUSSÕES}

Os coeficientes de variação ficaram entre 7,38 e 18,26\% (Tabela 2), o que demonstra homogeneidade dos tratamentos e alta confiabilidade nas estimativas das médias, pois, em experimentos realizados em campo cujo cultura avaliada seja milho, é exigido um CV inferior ou igual a 20\% [29].

Observou-se que todas as variáveis avaliadas nos 36 genótipos de milho apresentaram diferenças significativas ( $\mathrm{p} \leq 0,05$ e $\mathrm{p} \leq 0,01)$ (Tabela 2). Estes resultados demonstram que houve, no mínimo, uma cultivar diferindo das demais, sinalizando uma ampla variabilidade fenotípica observada entre híbridos e variedades que permitiram, com precisão, a caracterização de indivíduos superiores [30].

Tabela 2: Resumo da análise de variância com os tratamentos ajustados com recuperação da informação interblocos das variáveis, avaliadas na fazenda experimental da EMBRAPA - semiárido.

\begin{tabular}{lcccccccc}
\hline & & \multicolumn{8}{c}{ QM } \\
\cline { 3 - 9 } \multicolumn{1}{c}{ FV } & GL & DC & PP & Mfe & MS & PorMS & Mfo \\
\hline $\begin{array}{l}\text { Trat } \\
\text { (Ajust.) }\end{array}$ & 35 & $108,62^{*}$ & $0,03 *$ & $0,34^{*}$ & $0,0057^{* *}$ & $0,00039^{*}$ & $0,0017^{*}$ & $28408,9 * *$ \\
Resíduo & 25 & 23,99 & 0,016 & 0,29 & 0,0067 & 0,00037 & 0,0005 & 34350,18 \\
\hline
\end{tabular}




\begin{tabular}{lccccccc}
\hline Intrabl. & & & & & & & \\
\hline $\begin{array}{l}\text { Fator de } \\
\text { ajuste }\end{array}$ & 0,12 & 0,73 & 0,05 & 0,06 & 0,06 & 0,11 & 0,02 \\
\hline CV $(\%)$ & 9,42 & 7,38 & 16,08 & 18,26 & 13,86 & 7,55 & 17,07 \\
\hline Média & 51,96 & 1,72 & 3,34 & 0,44 & 0,13 & 31 & 1085,44 \\
\hline
\end{tabular}

* e **, significa, significativo a $1 \%$ e a $5 \%$ de probabilidade, respectivamente, pelo teste F. CV: Coeficiente de variação (\%); AP: Altura da Planta (cm); DC: Diâmetro do colmo (cm); PP: Peso de planta (kg); Mfe: Massa Fresca (kg); MS: Massa Seca (kg); PorMS: Porcentagem de Massa Seca e Mfo: Massa de Forragem (kg MS/ha).

No que diz respeito a qualidade da ensilagem, é necessário que o milho apresente elevada produção de matéria seca [31], visto que esta é uma das principais características que favorecem a fermentação da silagem [32]. De acordo com ZEOULA et al. [33] e PEREIRA et al. [34], o milho para silagem deve apresentar de $30 \%$ a $35 \%$ de matéria seca. Sendo assim, os genótipos avaliados foram considerados dentro da faixa aceitável, com média geral de $31 \%$ de massa seca (PorMS), garantindo assim boa qualidade da ensilagem. Além disto, esse resultado demonstra que os genótipos estavam na época correta de colheita para forragem.

Segundo KLEIN et al. [35], plantas de milho que apresentam maior porte são mais propícias a produzir silagem com maior porção de material fibroso, além de aumentar a resistência das plantas ao acamamento, muitas vezes provocado pela velocidade do vento. Por conta disto, a altura da planta e diâmetro do colmo, que obtiveram médias de $51,96 \mathrm{~cm}$ e 1,72 cm (Tabela 2), respectivamente, são de grande importância no rendimento de silagem do milho. Observou-se uma significativa influência do ambiente na altura das plantas. Isso ocorreu devido a correntes veranicos típicos da região, reforçando a potencialização de estudos genéticos para o desenvolvimento de materiais forrageiros tolerantes a seca nessas regiões.

SAH et al. [36] observaram em seu estudo uma limitação na altura da planta em ambientes com déficit hídrico quando comparados a locais mais favoráveis ao seu desenvolvimento, com uma redução de 127,81 m para 104,5 m. Isto acontece, pois, a seca afeta desde o estágio de plântulas até a maturidade fisiológica, influenciando a colheita, tanto de silagem quanto de grãos, em qualquer estádio de desenvolvimento [37].

Os dois primeiros componentes principais (CPs) contemplaram 83,9\% da variação total (Tabela 3). Este valor demonstra que os gráficos biplots possibilitam uma seleção segura dos genótipos, pois segundo YANG et al. [38] os dois primeiros CPS devem explicar pelo menos 60\% da variação e para Ferreira [39], quando se tem um número $\mathrm{k}<\mathrm{p}$ de $\mathrm{CP}$, ou seja, quando o número de $\mathrm{k} \mathrm{CP}$ é menor que $\mathrm{p}$ variáveis, adota-se o critério de pelo menos $70 \%$ da variação total.

Tabela 3: Autovalores, variação explicada, proporção acumulada e importância relativa (IR) dos cinco componentes principais $(\mathrm{CP})$, para realização da análise GT biplot.

\begin{tabular}{cccccc}
\hline CP & $\mathbf{1}$ & $\mathbf{2}$ & $\mathbf{3}$ & $\mathbf{4}$ & $\mathbf{5}$ \\
\hline Valor Singular & 4,11 & 1,76 & 0,97 & 0,12 & 0,03 \\
\%Explicada & 58,71 & 25,19 & 13,89 & 1,74 & 0,48 \\
\%Acumulada & 58,71 & 83,89 & 97,78 & 99,52 & 100 \\
\hline IR & 4,5 & 2,9 & 2,2 & 0,7 & 0,4 \\
\hline
\end{tabular}

A Importância Relativa (IR) traz evidências de que se algum CP apresentar IR com valores abaixo de 1.0 , este apresenta pouca informação, enquanto componentes que apresentam valores acima de 1.0 trazem importantes padrões, como informações de diferentes classes genotípicas e variáveis [17].

Contudo, a adoção do IR como critério de seleção de CP pode levar a poucos CPs quando se tem padrões que dominam e que são capazes de esconder fracas informações. Por outro lado, muitos CPs podem ser mantidos pela falta de fortes padrões. Assim, os primeiros dois componentes (4,5 e 2,9, respectivamente) apresentaram importantes padrões. Assume-se, então, que o GT biplot apresenta importantes informações sobre a interação entre as classes genéticas e as variáveis avaliadas para seleção do potencial forrageiro cultivado no Sertão de Sergipe.

O autovalor do primeiro CP (CP1) foi de 4,11, considerado muito significativo, já que a soma de todos os autovalores foi de 6,99. LEITE et al. [40] obtiveram 2,53 em seu CP1 ao selecionar genótipos de soja, com um total de autovalores de 6, enquanto HONGYU et al. [41] apresentaram um auto valor no CP1 de 
3,45 de um total de 6,97, ou seja, os dados obtidos na avaliação dos grupos de milho estão dentro do esperado e aceito.

A variável massa fresca (Mfe) apresentou o maior coeficiente de correlação, com o CP de maior explicação $(0,96)$ (Tabela 4). Sendo assim, esta é a variável de maior importância para a construção deste componente principal [41]. Para o CP2 e CP4, a massa fresca apresentou uma correlação fraca e negativa. As demais variáveis apresentaram correlações de média a forte no CP1, que é o de maior importância, pois explicou 58,71\% da variação total. De acordo com AL-NAGGAR et al. [42], a importância de um CP é dada de acordo com a variância total explicada por este.

Tabela 4: Os cinco componentes principais e suas respectivas correlações com as variáveis analisadas nos 36 genótipos de milho.

\begin{tabular}{llllllll}
\hline & MFo & DC & MS & MFe & AP & PorMS & PP \\
\hline CP 1 & 0,69 & 0,65 & 0,75 & 0,96 & $-0,65$ & $-0,63$ & 0,92 \\
CP 2 & 0,66 & $-0,62$ & 0,60 & $-0,15$ & $-0,07$ & 0,72 & 0,05 \\
CP 3 & 0,23 & $-0,33$ & $-0,21$ & 0,20 & 0,72 & $-0,24$ & 0,35 \\
CP 4 & 0,05 & 0,25 & 0,07 & $-0,05$ & 0,18 & 0,10 & $-0,02$ \\
CP 5 & $-0,08$ & $-0,03$ & 0,10 & 0,08 & 0,04 & $-0,005$ & $-0,05$
\end{tabular}

CP: Componente principal; AP: Altura da Planta (cm); DC: Diâmetro do colmo (cm); PP: Peso de planta (kg); Mfe: Massa Fresca (kg); MS: Massa Seca (kg); PorMS: Porcentagem de Massa Seca e Mfo: Massa de Forragem (kg MS/ha).

A capacidade de discriminação é importante, pois, a variável que não apresenta esta capacidade, não fornece informações ligadas aos genótipos, tornando-se então de pequena utilidade. Outra medida importante para uma variável avaliada é a representatividade, com relação a uma variável alvo. Se uma variável for não representativa, além de pouco útil, poderá fornecer informações tendenciosas sobre os genótipos avaliados [43]. Deste modo, a interpretação da capacidade de discriminação e representatividade das variáveis pode ser realizada no gráfico denominado "Discriminante vs Representativo" (Figura 1).

Os círculos concêntricos no Biplot ajudam a visualizar o comprimento dos vetores da variável, que é proporcional ao desvio padrão dentro das respectivas variáveis e é uma medida da capacidade de discriminação das variáveis. Assim, AP foi a única variável que não apresentou maior capacidade de discriminação das classes genotípicas dentre as variáveis analisadas.

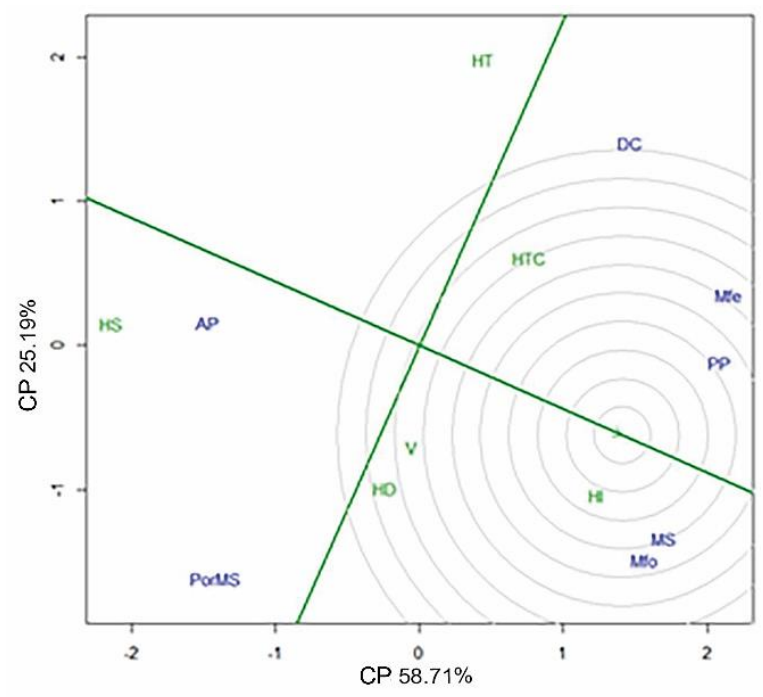

Figura 1: Discriminação e representatividade das variáveis que determinam o potencial forrageiro de diferentes classes genotípicas de milho. HS: Híbrido simples; HT: Híbrido triplo; HD: Híbrido duplo; HTC: Híbrido Top-cross; HI: Híbrido Intervarietal; V: variedade; AP: Altura da Planta (cm); DC: Diâmetro do colmo (cm); PP: Peso de planta (kg); Mfe: Massa Fresca (kg); MS: Massa Seca (kg); PorMS: Porcentagem de Massa Seca e Mfo: Massa de Forragem (kg MS/ha). 
A variável média, representada pelo menor círculo dado na Figura 1, também representada por uma pequena seta dentro deste círculo, tem as coordenadas médias de todos as variáveis de teste e o eixo da variável média (AVA) é a linha que passa pela variável média e a origem do biplot $[28,44]$. Quanto menor o ângulo formado com a AVA, mais representativa será a variável. Assim, as variáveis MS, PP e AP foram as mais representativas, entretanto, a AP não foi discriminatória.

As variáveis discriminatórias e não representativas, como DC, Mfe, Mfo e PorMS, são úteis para selecionar genótipos especificadamente adaptáveis ou para o descarte de genótipos instáveis [28, 44]. Pode-se então denominar super-variáveis para a seleção de genótipos com potencial forrageiro no sentido da instabilidade e estabilidade fenotípica para a região, sendo MEGAVAR1 (adaptados e instáveis) e MEGAVAR2 (não adaptados e estáveis). Sendo assim, as classes genotípicas pertencentes no MEGAVAR1 são HI, HTC, HD e V e para o MAGVAR2 foram os HS e HT. Recomenda-se nesse sentido, uma alternativa para a dinâmica de cultivo em ambientes caracterizados como semiárido, a utilização de genótipos da classe do MEGAVAR1 por apresentarem maior variabilidade.

O genótipo definido como "ideal" é representado no gráfico pelo vetor mais longo em CP1 (58,71\%) e CP2 (25,19\%) sem projeções [45], representado pela seta no centro dos círculos concêntricos (Figura 2). Embora esse genótipo ideal não exista na realidade, ele é usado como referência para a avaliação dos demais genótipos, quanto mais próximo estes estiverem do ideal, mais desejável ele é pelos melhoristas, no caso do presente trabalho este genótipo ideal é representado pela classe genotípica ideal. Os demais círculos concêntricos auxiliam a visualização da distância entre cada classe genotípica com a classe ideal. Deste modo, a classe genotípica denominada Híbrido Intervarietal, alocado no primeiro círculo concêntrico, é a mais próxima da classe "ideal" em termos de produtividade e estabilidade fenotípica.

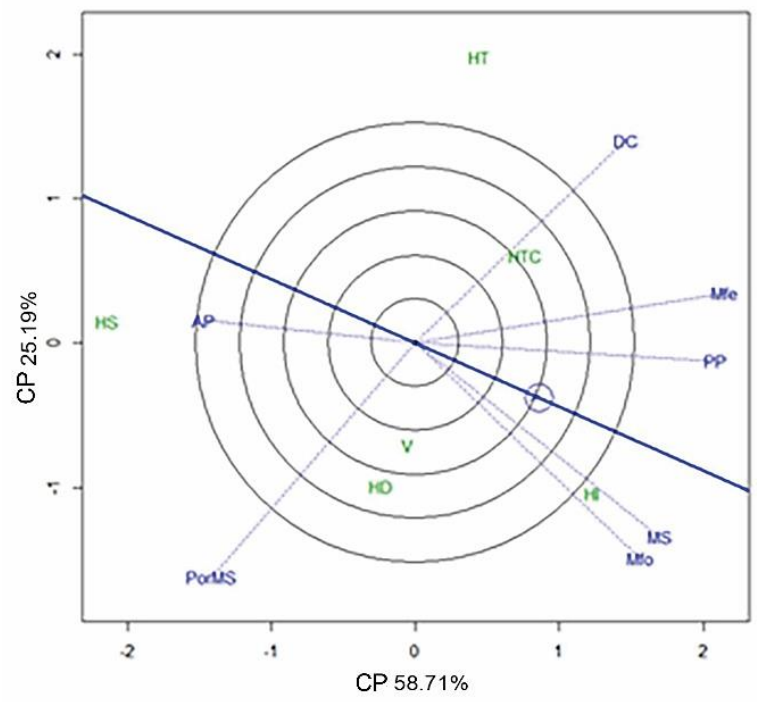

Figura 2: GT biplot comparando diferentes classes genéticas de milho avaliados quanto a produtividade e estabilidade fenotípica com a estimativa de um genótipo ideal para variáveis que determinam o potencial forrageiro da cultura. HS: Híbrido simples; HT: Híbrido triplo; HD: Híbrido duplo; HTC: Híbrido Top-cross; HI: Híbrido Intervarietal; V: variedade; AP: Altura da Planta (cm); DC: Diâmetro do colmo (cm); PP: Peso de planta (kg); Mfe: Massa Fresca (kg); MS: Massa Seca (kg); PorMS: Porcentagem de Massa Seca e Mfo: Massa de Forragem (kg MS/ha).

A correlação entre as variáveis determina a influência positiva ou negativa que uma variável tem sobre outra [46]. Segundo OLIVEIRA et. al. [46], no biplot, quando os ângulos entre as variáveis forem agudos (< $90^{\circ}$ ) eles são positivamente correlacionados, enquanto ângulos obtusos $\left(>90^{\circ}\right)$ são negativamente correlacionados. Os vetores formando um ângulo reto $\left(=90^{\circ}\right)$ não são correlacionados, enquanto aqueles formando ângulos de $180^{\circ}$ são fortemente correlacionados negativamente.

As variáveis Mfo e a MS apresentaram a maior correlação positiva (Figura 3), essa correlação já é esperada, pois o processo para o cálculo da massa de forragem é necessário o uso da massa seca na fórmula. No entanto, pode-se realizar uma seleção indireta de genótipos que apresentem uma maior massa seca visando obtenção de genótipos com maior massa de forragem por hectare.

O peso da planta (PP), medida importante para avaliação do potencial forrageiro de um genótipo, apresentou correlação positiva com Mfo, portanto materiais com altas estimativas de peso de planta podem gerar 
melhores resultados quanto a massa da forragem por hectare. Além disso, pode-se utilizar a variável PP como medida de seleção indireta, pois para a obtenção de Mfo há processamento destrutivo de amostras o que pode ser evitado com esse resultado.

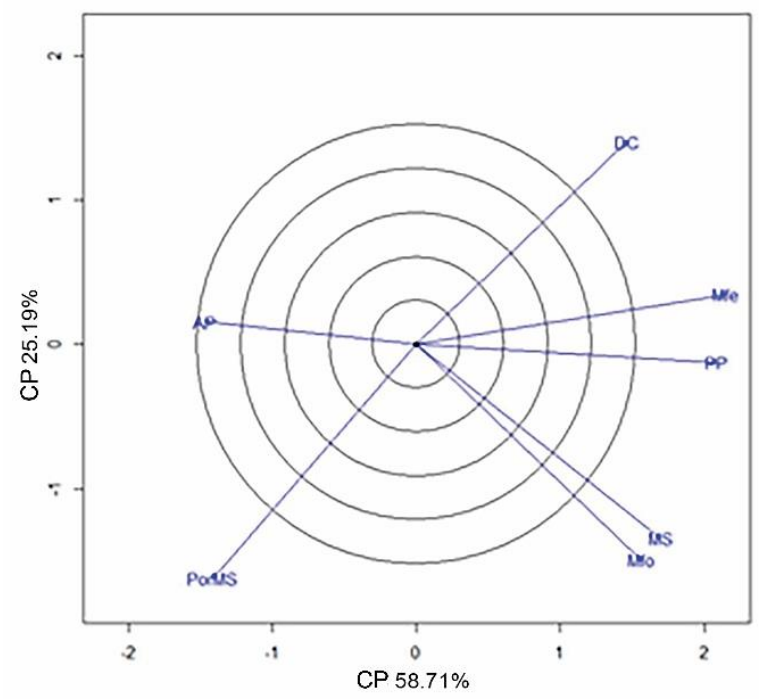

Figura 3: GT biplot representando o gráfico com os vetores das variáveis que determinam o potencial forrageiro de diferentes classes genotípicas de milho avaliados em condições semiáridas. HS: Híbrido simples; HT: Híbrido triplo; HD: Híbrido duplo; HTC: Híbrido Top-cross; HI: Híbrido Intervarietal; V: variedade; AP: Altura da Planta (cm); DC: Diâmetro do colmo (cm); PP: Peso de planta (kg); Mfe: Massa Fresca (kg); MS: Massa Seca (kg); PorMS: Porcentagem de Massa Seca e Mfo: Massa de Forragem (kg MS/ha).

A produtividade e estabilidade dos genótipos representados pelas classes genotípicas foram avaliadas a partir da coordenação da variável média (AVC) (Figura 4). Neste método uma variável ideal é definida a partir da média dos escores dos componentes principais de todas as variáveis, definido pelo pequeno círculo. A linha que passa pela origem do biplot e pela variável ideal é chamada de eixo da variável ideal e representa a AVC abscissa. A AVC ordenada é o eixo que passa pela origem do biplot e é perpendicular a AVC abscissa e indica um maior efeito da interação classes x variáveis e menor estabilidade, e ainda separa as classes que estão abaixo e acima da média [28, 44, 48].

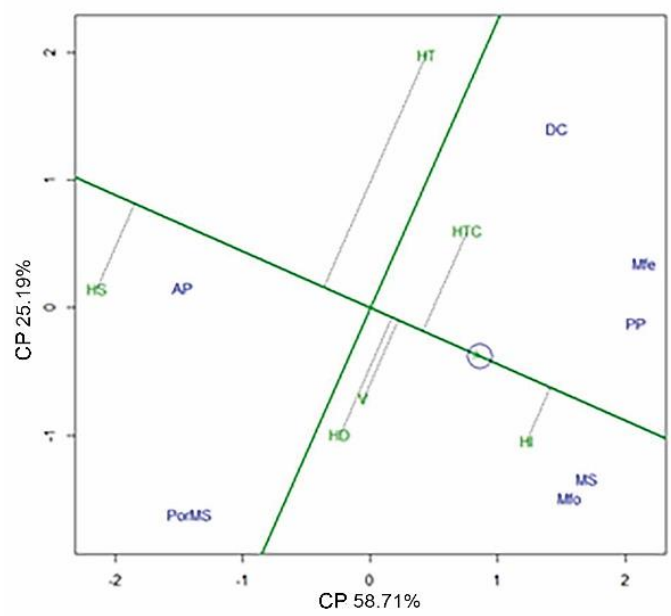

Figura 4: Adaptabilidade e estabilidade de seis classes genotípicas quanto a variáveis que determinam o potencial forrageiro de milho avaliados em condições semiáridas. HS: Híbrido simples; HT: Híbrido triplo; HD: Híbrido duplo; HTC: Híbrido Top-cross; HI: Híbrido Intervarietal; V: variedade; AP: Altura da Planta (cm); DC: Diâmetro do colmo (cm); PP: Peso de planta (kg); Mfe: Massa Fresca (kg); MS: Massa Seca (kg); PorMS: Porcentagem de Massa Seca e Mfo: Massa de Forragem (kg MS/ha). 
As classes genotípicas mais produtivas são os Híbridos Intervarietais, Híbridos Topcross, Variedades e Híbridos Duplos, nesta ordem. Estas classes apresentaram genótipos acima da média para as variáveis DC, Mfe, PP, MS e Mfo. Deve-se ressaltar a aptidão dos híbridos intervarietais para a massa de forragem, variável alvo desse estudo. Híbridos simples e triplos mostram-se inviáveis para o cultivo em ambientes com a dinâmica do semiárido, principalmente para o pequeno e médio produtor onde se observa a falta de tecnologias para exploração do potencial genético desses genótipos.
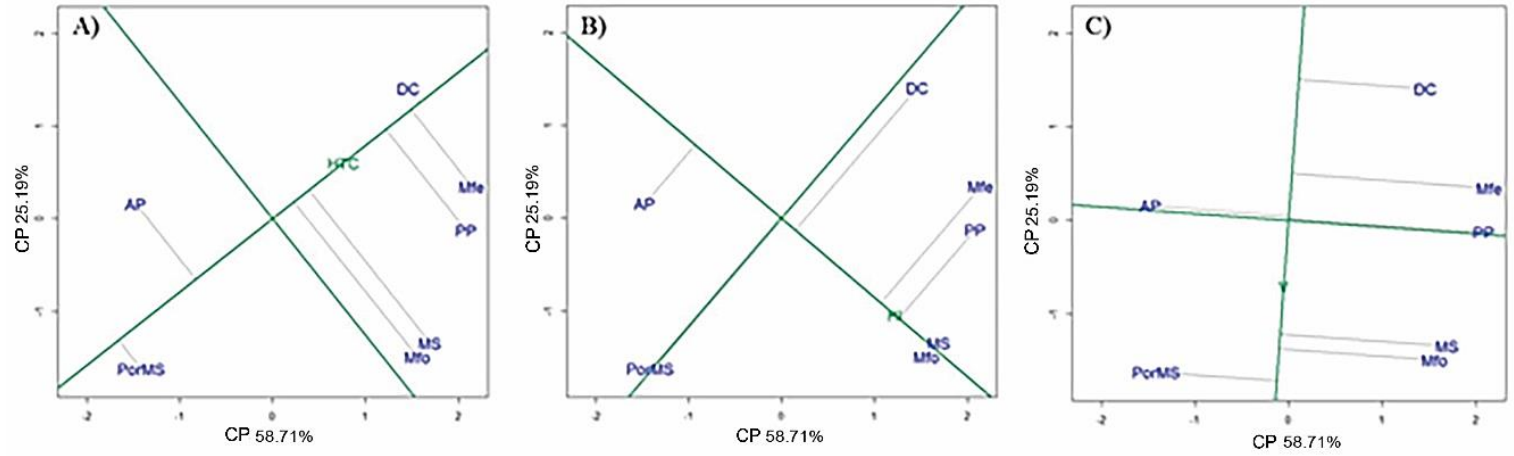

Figura 5: GT biplot representando desempenho individual dos híbridos simples (A), duplos (B) e triplos (C) com relação as variáveis que determinam o potencial forrageiro de diferentes classes genotípicas de milho avaliadas em clima semiárido. AP: Altura da Planta (cm); DC: Diâmetro do colmo (cm); PP: Peso de planta (kg); Mfe: Massa Fresca (kg); MS: Massa Seca (kg); PorMS: Porcentagem de Massa Seca e Mfo: Massa de Forragem (kg MS/ha).

As figuras 5 e 6 apresentam as aptidões intrínsecas a cada classe genotípica [48]. Segundo MATEI et al. [49] a linha do vetor das variáveis em relação a linha da classe genética representa a estabilidade da variável. Sabendo-se disto, foi observado que a classe genética HS apresentou uma tendência a ter a maior altura de planta e porcentagem de matéria seca (Figura 5A). Este híbrido corresponde ao comercial BRS 1055, e por obter uma alta produção de matéria seca, que é uma das principais características desejadas pelos produtores de milho para silagem [31], seu cultivo na região é de grande importância.

No entanto por ser um híbrido simples, deve estar aliado ao uso de alta tecnologia para exploração do seu potencial genético. Além disso, a falta de variabilidade genética, prejudicou a produtividade deste, devido ao estresse por deficiência hídrica ocorrida durante a fase final das avaliações.

Por outro lado, a variável PorMS não apresentou uma estabilidade alta, o que pode implicar nas médias quando a cultivar for replantada, pois, quando a estabilidade de uma variável é baixa, significa que a sua média pode variar quando avaliada em outro cultivo naquele mesmo ambiente, não propiciando uma segurança na indicação dos genótipos [50, 51, 52].
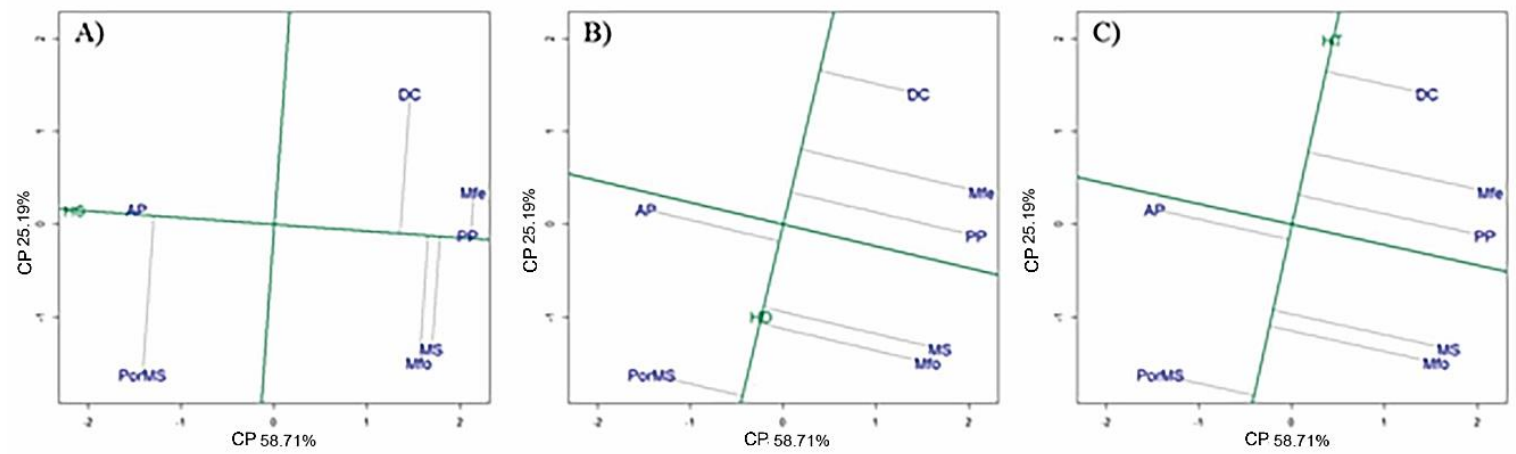

Figura 6: GT biplot representando desempenho individual dos híbridos topcross (A), híbridos intervarietal (B) e variedades (C) com relação as variáveis que determinam o potencial forrageiro de diferentes classes genotípicas de milho avaliadas em clima semiárido. AP: Altura da Planta (cm); DC: Diâmetro do colmo (cm); PP: Peso de planta (kg); Mfe: Massa Fresca (kg); MS: Massa Seca (kg); PorMS: Porcentagem de Massa Seca e Mfo: Massa de Forragem (kg MS/ha). 
O híbrido duplo (Figura 5B) apresentou a melhor média para massa seca e massa de forragem, ou seja, a cultivar comercial BR2121QPM foi superior para estas variáveis, lembrando que estas foram discriminatórias e representativas para o potencial forrageiro dos genótipos de milho. Por outro lado, a estabilidade dessas variáveis é baixa, enquanto o diâmetro do colmo e a porcentagem de massa seca são mais estáveis, mas não representam as maiores tendências médias para estes híbridos.

O híbrido triplo (Figura 5C), que corresponde a cultivar comercial BRS 3046, apresentou estimativa acima da média para altura da planta, massa seca, massa de forragem e porcentagem de massa seca. Com relação aos híbridos topcross (Figura 6A), que são os genótipos experimentais HTC-SP1, HTCms- CAPO, HTC771, HTC717, HTC795, HTC707, HTC781, HSmsxHTMV1, HTC697, HTCms15672 apresentaram as melhores média em massa seca, peso de planta e massa de forragem, porém, suas estabilidades nestas variáveis foram baixas, quando comparada a porcentagem de massa seca e diâmetro do colmo.

Os híbridos intervarietais (Figura 6B), que são os experimentais HI (771xHTMV1), HI (707x HTMV1), 98CV02, HIV 473451, HIV 2564260 foram superiores para as variáveis peso de planta, massa fresca, massa seca e massa de forragem, obtendo uma alta estabilidade nestas duas últimas variáveis. Fator importante a ser observado é a fase desses materiais, que por serem ainda experimentais apresentam alta aptidão para utilização em programas de melhoramento com objetivo para aumento na qualidade e quantidade no fornecimento de forragem para a região semiárida em foco.

Para as variedades (Figura 6C), que foi a classe genética com maior número de genótipos, representados pelos comerciais Sint 10771-BRS 4107, Sint 10795-BRS 4105, Potiguar-G13, BRS Gorutuba, CAPO, BR5037-Cruzeta-G19, AL AVARÉ e os experimentais Sint 10717, UFVM100(HS)C1, PC0904, IPR164, PC0905, Sint.Super Prec 1, MC 50, MC 20, MC 60, AL 2015, UFVM200(HS)C1, as melhores médias obtidas foram em massa seca e massa de forragem, porém suas estabilidades foram baixas, assim como em todas as demais variáveis.

\section{CONCLUSÕES}

Os híbridos intervarietais, representados por genótipos experimentais, apresentaram o maior potencial forrageiro nas condições de semiárido sergipano, sendo indicadas para serem inseridos em programas de melhoramento voltado a forragicultura na região.

Híbridos simples e triplos não são indicados para agricultores de baixa e média tecnologia quando cultivados em região semiárida para fins forrageiros, pois exigem altos níveis tecnológicos na área.

Híbridos duplos, topcross e variedades, por apresentarem alta variabilidade genética, são os mais indicados para produtores que possuem baixa e média tecnologia de produção, visando a dinâmica de cultivo em regiões semiáridas.

\section{AGRADECIMENTOS}

Este trabalho foi financiado pela Coordenação de Pesquisa da Universidade Federal de Sergipe - Brasil (COPES).

\section{BIBLIOGRAFIA}

[1] SOLOGUREN, L., "IMPORTÂNCIA: Demanda mundial cresce e Brasil tem espaço para expandir produção”, In: CAIXETA-FILHO, J.V., NUSSIO, L.G. (org.). Milho: Brasil amplia cultivo para atender demanda crescente. 1. ed., chapter 01, Piracicaba, Brasil, Visão agrícola - USP ESALQ, 2015.

[2] FAUSTINO, T.F., DIAS E SILVA, N.C., LEITE, R.F., et al. "Utilização de grão de milho reidratado e casca de café na alimentação animal”, Revista Científica Rural, v. 22, n. 1, pp. 259-275, 2020.

[3] SANCHES, A., ALVES, L.R.A., BARROS, G.S.C., "Oferta e demanda mensal de milho no Brasil Impactos da segunda safra”, Revista da Política Agrícola, v. 27, n. 4, pp. 73-97, 2018.

[4] ARTUZO, F.D., FOGUESATTO, C.R., MACHADO, J.A.D., et al. "O potencial produtivo brasileiro: uma análise histórica da produção de milho", Revista em Agronegócio e Meio Ambiente, v. 12, n. 2, pp. 515 $540,2019$.

[5] CONTINI, E., MOTA, M.M., MARRA, R., et al. "Série desafios do agronegócio brasileiro (NT2): Milho 
- Caracterização e Desafios Tecnológicos",. Empresa Brasileira de Pesquisa Agropecuária - Embrapa, pp. 145, 2019.

[6] RADAR - Agrojornalismo em tempo real., Milho: USDA estima produção mundial 2020/21 em 1,163 bilhão de toneladas. Canal Rural, 2020, https://www.canalrural.com.br/radar/milho-usda-estima-producaomundial-2020-21-em-1163-bilhao-de-

tonela-

das/\#: :text=O\%20relat $\%$ C3\%B3rio\%20de $\% 20$ oferta $\% 20 \mathrm{e} \% 20$ demanda $\% 20$ mundial $\% 20$ de $\% 20$ milho $\% 20 \mathrm{~d}$ o,de\%20toneladas\%20indicadas\%20em\%20junho/. Acessado em fevereiro de 2021.

[7] CONAB - Companhia Nacional de Abastecimento., "Acompanhamento da safra brasileira - Grãos", Ministério da agricultura, pecuária e abastecimento, v. 7, n. 12, pp. 1-64, 2020. (Observatório Agrícola).

[8] LIMA, P.V.P.S., MENDES, C.M., ROCHA, L.A., et al. "No rastro da vulnerabilidade às secas: uma análise da produção de grãos no semiárido brasileiro", Revista Eletrônica Documento Monumento, v. 19, n. 1, pp. 183-196, 2016.

[9] SILVA, C.B., SILVA, J.C., OLIVEIRA, F.A., et al., "Milho verde em região semiárida: Práticas relacionadas a produção agrícola”, Brazilian Journal of Development, v. 6, n.6, pp.41078-41088, 2020.

[10] LOPES, J.R.F, DANTAS, M.P., FERREIRA, F.E.P., "Variabilidade da precipitação pluvial e produtividade do milho no semiárido brasileiro através da análise multivariada", Nativa, v. 7, n. 1, pp. 77-83, 2019.

[11] BRITO, L.T.L., Cadernos do Semiárido: a água de chuva como potencial para aumentar a disponibilidade hídrica no semiárido brasileiro, 2 ed., Recife, CREA-PE, 2017.

[12] OLIVEIRA, E.M., SÁ, E.S.S.C.G., SELVA, V.S.F., et al. "Produção de feijão e milho com base na precipitação em área susceptível à desertificação no Seridó da Paraíba", Revista GeoNordeste, Ano XXX, n. 3, pp. 227-245, 2019.

[13] SANTOS, W.M., SOUZA, R.M.S., SOUZA, E.S., et al. "Variabilidade espacial da sazonalidade da chuva no semiárido brasileiro", Journal of Environmental Analysis and Progress, v. 2, n. 4, pp. 368-376, 2017.

[14] VIÇOSI, K.A., FERREIRA, A.A.S., OLIVEIRA, L.A.B., et al. "Estresse hídrico simulado em genótipos de feijão, milho e soja”, Revista de Agricultura Neotropical, v. 4, n. 5, pp. 36-42, 2017.

[15] SILVA, J.A., SOUZA, N.G.M., MAIA, J.M., et al. "Políticas públicas voltadas para a agricultura familiar no semiárido brasileiro", Revista BioFarm, v. 12, n. 03, pp. 1-13, 2016.

[16] CASTRO, C.N., "Sobre a agricultura irrigada no semiárido: uma análise histórica e atual de diferentes opções de política", Texto para Discussão (IPEA), v. 2369, pp. 1-56, 2018.

[17] CRISPIM, A.B., SOUZA, M.J.N., QUEIROZ, P.H.B., et al. "A questão da seca no semiárido nordestino e a visão reducionista do estado: a necessidade da desnaturalização dos problemas socioambientais", $R e$ vista de Educação Ambiental, v. 21, n. 2, pp. 39-59, 2016.

[18] COUTO, C.A., SILVA, E.M., SILVA, A.G., et al. "Desempenho de Cultivares de Milho Destinados para Produção de Milho Verde e Silagem", Fronteiras: Journal of Social, Technological and Environmental Science, v. 6, n. 1, pp. 232-251, 2017.

[19] VELHO, J.P., ZARDIN, P.B., JOBIM, C.C., et al. "Meta-analysis of corn plants, green fodder (ensilage), and silages of different types of maize hybrids used in experimental conditions in Brazil", Semina: Ciências Agrárias, v. 41, n. 1, pp. 237-254, 2020.

[20] CARNEIRO, W.M.A., "Produção de Grãos do Nordeste em 2020", DEE-Diário Econômico ETENE, Ano III, n. 3, 2020.

[21] SILVA, J.A., SOUZA, N.G.M., MAIA, J.M., et al. "Políticas públicas voltadas para a agricultura familiar no semiárido brasileiro", Journal of Biology \& Pharmacy and Agricultural Management, v. 12, n, 03, pp. $1-13,2016$

[22] ROSSI, E.S., FARIA, M.V., MENDES, M.C., et al. "Características bromatológicas do grão e forragem de híbridos de milho com diferentes texturas de grãos”, Revista Brasileira de Ciências Agrárias, v. 11, n. 2, pp. 132-141, 2016.

[23] PATERNIANI, M.E.A.G.Z., BERNINI, C.S., GUIMARÃES, P.S., et al. "Estratégias de melhoramento para tolerância à seca em germoplasma de milho tropical", Singular: Meio Ambiente e Agrárias, v. 1, n. 1, pp. 19-24, 2019.

[24] LOPES, J.R.A., BEZERRA, J.M., ALMEIDA, N.M.D.P., et al. "Águas subterrâneas como alternativa de subsistência em uma comunidade rural no semiárido brasileiro", Seção Estudos de Caso e Notas Técnicas, pp. 1-6, 2020.

[25] ALVAREZ, C.A., STAPE, J.L., SENTELHAS, P.C., et al. "Köppen's climate classification map for Brazil”, Meteorologische Zeitschrift, v. 22, n. 6, pp. 711-728, 2013.

[26] INMET- Instituto Nacional de Meterologia, "Estação Meterológica de Nossa Senhora da Glória SE", https://www.inmet.gov.brlportal Acessado em julho de 2018. 
[27] SOBRAL, L.F., VIEGAS, P.R.A., SIQUEIRA, O.J.W., et al. Recomendações para o uso de corretivos e fertilizantes no estado de Sergipe. 1 ed., Aracaju, Embrapa Tabuleiros Costeiros, 2007.

[28] YAN, W., TINKER, N.A., "Biplot analysis of multi-environment trial data: principles and applications", Canadian Journal of Plant Science, v. 86, n. 3, pp. 623-645, 2006.

[29] GURGEL, F.L., FERREIRA, D.F., SOARES, A.C.S.E., O Coeficiente de Variação como Critério de Avaliação em Experimentos de Milho e Feijão, 1. ed., Belém, Embrapa Amazônia Oriental, 2013.

[30] TAVARES, T.C.O., SOUSA, S.A., LOPES, M.B.S., et al. "Divergência genética entre cultivares de feijão comum cultivados no estado do Tocantins", Revista de Agricultura Neotropical, v. 5, n. 3, pp. 76-82, 2018.

[31] PAZIANI, S.F., DUARTE, A.P., NUSSIO, L.G., et al. "Características agronômicas e bromatológicas de híbridos de milho para produção de silagem", Revista Brasileira de Zootecnia, v. 38, n. 3, pp. 411-417, 2009.

[32] BASSO, F.C., LARA, E.C., ASSIS, F.B., et al. "Características da fermentação e estabilidade aeróbia de silagens de milho inoculadas com Bacillus subtilis", Revista Brasileira de Saúde e Produção Animal, v. 13, n. 4, pp. 1009-1019, 2012.

[33] ZEOULA, L.M., BELEZE, J.R.F., CECATO, U., et al. "Avaliação de Cinco Híbridos de Milho (Zea mays, L.) em Diferentes Estádios de Maturação. 4. Digestibilidade da Matéria Seca, Matéria Orgânica e Fibra em Detergente Neutro da Porção Vegetativa e Planta Inteira", Revista Brasileira de Zootecnia, v. 32, n. 3, pp. 567-575, 2003

[34] PEREIRA, M.N., PINHO, R.G.V., BRUNO, R.G.S., et al. "Ruminal degradability of hard or soft texture corn grain at three maturity stages", Scientia Agricola, v. 61, n.4, pp. 358-363, 2004.

[35] KLEIN, L. J., VIANA, A. F. P., ADAMS, S. M., et al. "Desempenho produtivo de híbridos de milho para a produção de silagem da planta inteira", Revista Brasileira de Milho e Sorgo, v. 17, n. 1, pp. 101-110, 2018.

[36] SAH, R.P., CHAKRABORTY, M., PRASAD, K., et al. "Impact of water defcit stress in maize: Phenology and yield componentes", Scientific Reports, v. 10, n. 2944, pp. 1-14, 2020.

[37] ADEWALE, S.A., AKINWALE, R.O., FAKOREDE, M.A.B., et al. "Genetic analysis of droughtadaptive traits at seedling stage in early-maturing maize inbred lines and field performance under stress conditions", Euphytica, v. 214, n, 145, pp. 1-18, 2018.

[38] YANG, R.C., CROSSA, J., CORNELIUS, P. L., et al. "Biplot analysis of genotype $\times$ environment interaction: Proceed with caution", Crop Science, v. 49, n. 5, pp. 1564-1576, 2009.

[39] FERREIRA, D.F., Estatística Multivariada, 2. ed., Lavras, UFLA, 2011.

[40] LEITE, W.S., PAVAN, B.E., ALCÂNTARA-NETO, F., et al. "Multivariate exploratory approach and influence of six agronomic traits on soybean genotypes selection", Nativa, v. 4, n. 4, pp. 206-210, 2016.

[41] HONGYU, K., SANDANIELO, V.L.M., OLIVEIRA-JUNIOR, G.J., "Análise de Componentes Principais: resumo teórico, aplicação e interpretação”, E\&S - Engineering and Science, v. 1, n. 5, pp. 83-90, 2015.

[42] AL-NAGGAR, A.M.M., SHAFIK, M.M., MUSA, R.Y.M., "Genetic Diversity Based on Morphological Traits of 19 Maize Genotypes Using Principal Component Analysis and GT Biplot", Annual Research \& Review in Biology, v. 35, n. 2, pp. 68-85, 2020.

[43] YAN, W., KANG, M.S., GGE biplot analysis: a graphical tool for breeders, geneticists, and agronomists, 1. ed., Boca Raton, CRC Press, 2002.

[44] YAN, W., KANG, M.S., MA, B. et al. "GGE Biplot vs AMMI analysis of genotype-by-environment data", Crop Science, v. 47, n. 2, pp. 643-653, 2007.

[45] SANTOS, A., AMARAL-JÚNIOR, A.T., KUROSAWA, R.N.F., et al. "GGE Biplot projection in discriminating the efficiency of popcorn lines to use nitrogen", Ciência e Agrotecnologia, v. 41, n. 1, pp. 22-31, 2017.

[46] FIGUEIREDO-FILHO, D.B., SILVA-JÚNIOR, J.A., "Desvendando os Mistérios do Coeficiente de Correlação de Pearson (r)", Revista Política Hoje, v. 18, n. 1, pp. 115-146, 2009.

[47] OLIVEIRA, T.R.A., GRAVINA, G.A., OLIVEIRA, G.H.F., et al. "The GT biplot analysis of green bean traits", Ciência Rural, v. 48, n. 6, pp. 1-6, 2018.

[48] YAN, W., "GGE biplot vs. AMMI graphs for genotype-by-environment data analysis", Journal of the Indian Society of Agricultural Statistics, v. 65, n. 2, pp. 181-193, 2011.

[49] MATEI, G., WOYANN, L.G., DALLÓ, S.C., et al. "Agronomic performance of modern soybean cultivars in multi-environment trials", Pesquisa Agropecuária Brasileira, v. 52, n. 7, pp. 500-511, 2017.

[50] MELO, L.C., MELO, P.G.S., FARIA, L.C., et al. "Interação com ambientes e estabilidade de genótipos de feijoeiro-comum na Região Centro-Sul do Brasil”, Pesquisa Agropecuária Brasileira, v.42, n.5, pp.715- 
$723,2007$.

[51] BORÉM, A., Melhoramento de plantas. 5. ed., Viçosa, Editora UFV, 2009.

[52] SANTOS, A., CECCON, G., TEODORO, P.E., et al. "Adaptability and stability of erect cowpea genotypes via REML/BLUP and GGE Biplot”, Bragantia, v. 75, n. 3, pp. 299-306, 2016.

\section{ORCID}

Eduarda Santos Silveira

https://orcid.org/0000-0002-8228-8399

Maisa Nascimento Carvalho

https://orcid.org/0000-0001-7620-4593

Beatriz Barreto de Lima

https://orcid.org/0000-0002-1589-0726

Tâmara Rebecca Albuquerque de Oliveira

http://orcid.org/0000-0003-4418-1547

Gustavo Hugo Ferreira de Oliveira

http://orcid.org/0000-0002-3839-6261 